\title{
Human rights and housing unaffordability: Applying policy practice engagement to a wicked problem
}

Michael Webster, University of Auckland, Aotearoa New Zealand

\begin{abstract}
INTRODUCTION: In working with marginalised communities, social workers are confronted with the consequences of housing unaffordability. The 1948 Universal Declaration of Human Rights (UDHR), adopted by Aotearoa New Zealand, identifies housing deprivation as a human right of relevance to social work. This study explores the application of the Policy Practice Engagement (PPE) framework (Gal \& Weiss-Gal, 2015) as a tool by which social workers can contribute to policy-making processes to address the human right to affordable housing.

METHOD: The project used a descriptive/exploratory design. Data were collected by semistructured interviews of eight subject matter experts in housing affordability: two public sector economists; one private sector economist/developer; two public sector urban planners; one public policy advisor; one non-governmental policy analyst; and one private sector housing strategist. Data were analysed thematically, followed by an inter-rater process.
\end{abstract}

FINDINGS: Participants identified human rights as relevant to the wicked problem (Grint, 2005) of housing affordability. Participants also identified political, economic and environmental factors impacting affordable housing. They considered that these factors are found in local body planning regulations, leading to land supply constraints. Some participants considered that housing unaffordability is the price paid to live in liveable cities.

CONCLUSIONS: The PPE framework offers a conceptual structure through which social workers can address housing unaffordability. By understanding the factors causing unaffordability, social workers are enabled to examine why and how they should contribute to policy processes.

Keywords: Housing unaffordability; policy practice engagement; Universal Declaration of Human Rights

In October 2018, the Minister of Education in Aotearoa New Zealand's government, the Hon Chris Hipkins delivered a speech to the Post Primary Teachers Association. In it he drew the attention of his audience to what he had earlier described in Parliament as the "housing crisis":

Poverty. That's why too many of our kids turn up to school hungry. Too tired and too undernourished to learn. That's why too many of our kids living in damp, squalid rentals turn up at our hospitals - with preventable illnesses. About 42,000 children go to hospital every year with infectious and respiratory diseases that are largely the result of cold, damp, mouldy homes? We can do better than having our children
AOTEAROA

NEW ZEALAND SOCIAL WORK 33(4), 31-46.

CORRESPONDENCE TO: Michael Webster m.webster@auckland.ac.nz 
attend school from the back of a car seat. Or at best, from the bedroom of a motel. That's why we have all committed to building 100,000 affordable homes for New Zealand families and to building 6,400 new public houses for families in need. (Hipkins, 2018)

Although political in nature, Hipkins' speech appropriately introduces the subject matter of this article: the human right to affordable housing enshrined in the Universal Declaration of Human Rights [UDHR] (United Nations General Assembly [UNGA], 1949). Starting with a definition of housing affordability and describing homelessness, this introduction will set out relevant themes for social workers in Aotearoa New Zealand needed to address the housing crisis: housing affordability as a "wicked problem" (Grint, 2005) and the Policy Practice Engagement [PPE] framework as a tool enabling social workers to change societal structures (Gal \& WeissGal, 2015). This article's intended audience are social workers employed in the housing provision sector.

The context of the author's current research provides the rationale for applying "diverse fields and types of practice" (Gal \& WeissGall, 2015, p. 1084) proposed by PPE. In late 2020, an Infrastructure Initiative group was set up in the University of Auckland comprising two civil and environmental engineers; a mechanical engineer; a health researcher who is also a medical doctor; an international management researcher focusing on the United Nations Sustainable Development Goals [SDGs]; an urban infrastructure planner; a constitutional lawyer; a computer scientist in the domains of architecture, engineering, and construction; and a research impact specialist. The author's contribution focuses on people's wellbeing, and housing affordability in urban environments. The purpose of the group is to apply transdisciplinary research to create a better infrastructure in Aotearoa New Zealand.
In pursuing that purpose, workshops with extra-university infrastructure experts were held, a research proposal is being constructed, and interfaculty lecturing has taken place. Transdisciplinary research is defined as:

Research efforts conducted by investigators from different disciplines working jointly to create new conceptual, theoretical, methodological, and translational innovations that integrate and move beyond discipline-specific approaches to address a common problem. (Harvard T. H. Chan School of Public Health, 2021)

While PPE cannot be described as transdisciplinary, synergies exist between the multiple routes for policy engagement by social workers described by Gal and WeissGal (2015) and the innovation of different disciplines working jointly to address a common problem (Harvard T. H. Chan School of Public Health, 2021).

\section{Housing affordability}

To define housing affordability, economists determine median household income, "the point where half the population is above and half below the stated amount" (Statistics New Zealand / Tatauranga Aotearoa, 2021, p. 6). For housing to be affordable, economists use a 3:1 ratio of the median house price to median household income; i.e., a dwelling should not cost more than three times the median household income (Eaqub \& Eaqub, 2015; Parker, 2015). By 2015, the median price of a home in New Zealand's most unaffordable city, Auckland, was $\$ 765,000$, equating to 9.6 times the median income of $\$ 79,356$ (Parker, 2015, pp. 40, 41).

\section{Homelessness}

Homelessness represents the extreme end consequence of the housing affordability crisis. Drawing on census figures from 2001, 2006 and 2018, Amore (2019) reports 
on the incidence of homelessness as a stark reminder of the human cost of this crisis. People subjected to a "lack of access to minimally adequate housing" [LAMAH] (Amore, 2019, p. 224) amounted to 28,917 in 2001 (77.4 per 10,000 people) and 33,946 in 2006 (84.3 per 10,000). The equivalent 2018 census figure is absolutely and proportionately higher: 41,644 (88.6 per 10,000). Woolley (2014) suggests that "we also know that many people who are homeless are never counted, living in caravan parks, in overcrowded houses [and that] homelessness in regions such as Auckland and Christchurch is intensifying" (2014, p. 1). Social workers are particularly concerned with homelessness (Johnson et al., 2018, p. 35).

Article 25 of the UDHR-endorsed by Aotearoa New Zealand-states that "Everyone has the right to a standard of living adequate for the health and wellbeing of himself [sic] and of his [sic] family, including housing and medical care" (UNGA, 1949). Because human rights underpin social work globally and locally (International Federation of Social Workers [IFSW], 2018; Aotearoa New Zealand Association of Social Workers [ANZASW], 2019), article 25 of the UDHR is of specific relevance to social work practice in New Zealand. The Human Rights Commission (Human Rights Commission Te Kāhu Tika Tangata [HRCTKTT] (2017) describes the human right to adequate housing in New Zealand as a "binding legal obligation of the State" (HRCTKTT, 2017, p. 1).

In considering political and economic factors contributing to housing unaffordability, the author proposes that unaffordability is a "wicked problem" defined by Grint (2005) as "complex and often intractable...there is no 'right' or 'wrong' answer. There are better or worse alternatives" (Grint, 2005, p. 1473). When considering factors relevant to housing unaffordability, the true nature of a wicked problem emerges. From where does unaffordability originate? Political policy platforms? Monetary policy on interest rates?
Tax as an instrument of government's fiscal policy and its spending actions? Perhaps town planning? Rittel and Webber (1973) capture this issue: "The formulation of a wicked problem is the problem!" (1973, p. 161, emphasis in original).

Social work is mandated to "engage in action to change the structures of society that create and perpetuate injustice" (ANZASW, 2019, p. 7 , emphasis added). This article will explore the potential for change in the context of the housing unaffordability crisis through the Policy Practice Engagement framework [PPE] (Gal \& Weiss-Gal, 2015). The PPE offers a conceptual framework to examine why and how social workers should engage in policy practice. This article proposes that, by applying the PPE framework, social workers in Aotearoa New Zealand will be enabled to engage with policy advisors and decisionmakers responsible for the complex problem of unaffordability. The PPE framework will be discussed in the literature review informing this research.

Following this introduction, the article will set out a literature review describing the human rights challenge in housing unaffordability; draw on relevant literature from urban economics and environmental sustainability; discuss urban planning policies; and most significantly, explore the PPE proposed by Gal and Weiss-Gal (2015). Second, the ethics consent required for the research; methodology used; the principles informing the research process; and the rationale for selecting participants from diverse professional backgrounds (Table 1) will be described. Third, results from data analysis will be given, followed, fourth, by a discussion of the literature including the PPE and the findings. Last, a conclusion will address the implications for social work practice by applying the PPE.

The aims of this article are informed by the view that housing unaffordability should be treated as a human rights challenge of prime concern to social workers in Aotearoa 
New Zealand. Those aims are, first, to articulate a practical pathway for social workers to address that challenge consistent with the mandate in our Code of Ethics to "engage in action to change the structures of society that create and perpetuate injustice" (ANZASW, 2019, p. 7). The second, interrelated, aim is to propose the PPE framework (Gal \& Weiss-Gal, 2015) as the tool by which that pathway may be effectively applied.

\section{Literature review}

In order to understand and address the issues relating to housing unaffordability, the knowledge contained in disciplines like urban economics, city planning, and environmental engineering is essential. Kemp et al. (2018) note that, to be effective and transformative "in the context of rising economic inequality" social work "must form new partnerships [for example] with urban planning and environmental engineering" (2018, pp. 4, 6). Unaffordable housing represents a specific dimension of that "rising economic inequality." For that reason, this literature review will draw from urban economics, environmental sustainability, urban planning policies, human rights and social justice, and the PPE (Gal \& Weiss-Gal, 2015). Exploring these disciplines is intended to provide housing sector social workers with at least an introductory knowledge to understand the wicked problem of unaffordability.

This review also draws on the "person-inenvironment" concept as a long-accepted approach in the social work profession (Gall \& Weiss-Gall, 2015; Simmons, 2012). In their survey of 123 jurisdictions, Tay and Diener (2011) assessed the place of essential accommodation and other basic human needs in these terms:

Basic needs for food and shelter were satisfied when in the past 12 months a respondent (a) had enough money for food, (b) had enough money for shelter, and (c) did not go hungry. (Tay \& Diener, 2011, p. 356)
This definition falls under the human rights housing provision (Article 25) of the UDHR cited earlier and is therefore a critical expectation for informed social work practice. To be effective in the housing policy context, social workers must also understand the essentials of city planning and economics to enable the development of the partnerships proposed by Kemp et al. (2018).

\section{Human rights and housing unafford- ability in Aotearoa New Zealand}

The statistical base which demonstrates the existence of an unaffordability crisis and, in particular, homelessness, is now presented in the light of societal injustice. Increasing homelessness levels noted by Amore (2019) are the evidence of the breach of human rights if in fact Aotearoa New Zealand is committed to Article 25 of the UDHR. The Human Rights Commission (Human Rights Commission Te Kāhu Tika Tangata [HRCTKTT] (2017) has set out its commitment to "the human right to adequate housing in New Zealand" by describing it as a "binding legal obligation of the State" (HRCTKTT, 2017, p. 1). Affordability means that "housing costs should be at such a level so as not to compromise the attainment of other basic needs [such as] buying food" (HRCTKTT, 2017, p. 2).

The announcement, on August 2, 2021, of a "national enquiry into the housing crisis" by the Human Rights Commission (Hunt, 2021) suggests that the Commission is re-asserting its concern about the issue. The Commissioner Paul Hunt sets out the intention of the HRCTKTT to "clarify what the right to a decent home means... an affordable, healthy, accessible home" (Hunt, 2021). Mr Hunt asserts that "serial governments bear a heavy responsibility for this massive human rights failure which is blighting lives and communities...this housing crisis is also a human rights crisis" (Hunt, 2021). 
The author suggests that social workers are more likely to take note of this initiative by the HRCTKTT than the citation of statistical evidence of the 3:1 ratio of median house prices vis-à-vis median household incomes. Such statistics fail to adequately communicate the impact on marginalised communities of homelessness as the sharp end of unaffordability. Practitioners working in housing provision are familiar with that "sharp end."

\section{Housing and environmental regulations}

Some research participants identified environmental planning regulations as a significant driver of unaffordability. These regulations have been influenced in Aotearoa New Zealand by the sustainable development goals (SDGs) developed by the United Nations. Originating in the "Rio Declaration" of 1992, by 2015 the SDGs had become known as Agenda 2030 (Ministry of Foreign Affairs \& Trade [MFAT], n.d.; UNGA, 2015). The SDGs apply environmental sustainability to urban planning policies-explicitly, the impact of cities on global climate (UNGA, 2015, pp. 9, 35). The SDGs in themselves are applicable in Aotearoa only if enacted in law, but the Ministry for the Environment (MfE) notes that environmental sustainability policies have contributed to the economic dimension of housing affordability (MfE, 1993, 2016, 2018). The Rio Declaration informed the Resource Management Act which, although currently under review, underpins government thinking on urban planning (MfE, 1993, p. 5). The environment was no longer to be treated as available for cost-free exploitation.

The commitment to sustainability is politically bipartisan but has arguably attracted a higher profile since the formation of the Ardern (Labour-led) government in 2017, re-elected with an absolute majority in 2020. The priority accorded to the issue is illustrated by a speech delivered in March 2018 by the environment minister, the Hon
David Parker, in which he unequivocally described climate change as the world's greatest environmental challenge (Parker, 2018). Consistent with the call by Agenda 2030 (UNGA, 2015) to minimise the influence of cities on global climate, environmentally friendly policies have been introduced into urban planning-but there has been a consequence. Integrating environmental concerns into urban planning and infrastructure is estimated to have cost $\$ 530,000$ for an average home (Treasury, 2017, p. 22). This is arguably another manifestation of Grint's (2005) “wicked problem." Weaver's (1984) observation that "ideas have consequences" - in this instance, the commitment of urban planning to environmental sustainability-is illustrated by that additional cost. To address that cost by increasing housing supply, Treasury advocated the removal of rural-urban boundaries (Treasury, 2017, p. 22), a call taken up by the government (Twyford, 2019).

In recent years, social work literature overseas and in Aotearoa has addressed environmental sustainability. Lena Dominelli's (2012) Green Social Work made an eloquent plea for the profession to become involved in "caring for the environment" (2012, p. 2); but Dominelli also noted that social work's voice has been virtually absent in taking collective action over damp, mouldy housing. Similarly, Carole Adamson's (2014) article calls for the extension of social work's commitment to the natural world.

\section{Applying a PPE framework}

The PPE framework, created by Gal and Weiss-Gal (2015), poses two questions of direct pertinence to this article:

Why do some social workers seek to influence social policy while others do not? How do social workers that engage in policy practice seek to impact policy formulation and what influences their chosen route to affect policy?

(2015, p. 1083) 
Gal and Weiss-Gal answer their first question-why social workers seek to influence policy - by proposing certain external and internal motivators of social workers to engage in that field. These motivators are determined by their professional socialisation, individual characteristics, and values (Figure 1). Socialisation is developed externally: first, by professional discourse, the expectation that practitioners will engage in policy practice; second, through expected activities as set out in their codes of ethics; and third, by attitudes engendered in degree courses. Internal motivators are derived from the individual values and personal interests of a practitioner (Gal \& Weiss-Gal, 2015, pp. 1095, 1096). They cited Gray et al. (2002) who noted that social workers in Aotearoa are indeed active in the policy arena.
Responding to the second question-how social workers engage in policy-falls under the opportunity afforded by political institutions of the jurisdiction and the influence of organisational culture on facilitating action. Facilitation addresses the extent to which social work organisational culture influences policy practice activities. Organisational culture (Schein \& Schein, 2016) simultaneously influences and is influenced by internal and external motivators, as already discussed (Gal \& Weiss-Gal, 2015, p. 1097). It will be discussed under the "Facilitation" subheading. The three "legs" in Figure 1, opportunity; facilitation; and motivation directly influence why and how social workers apply PPE. Social workers who understand and apply the framework are enabled to engage

Figure 1 Policy Practice Engagement (PPE) Conceptual Framework

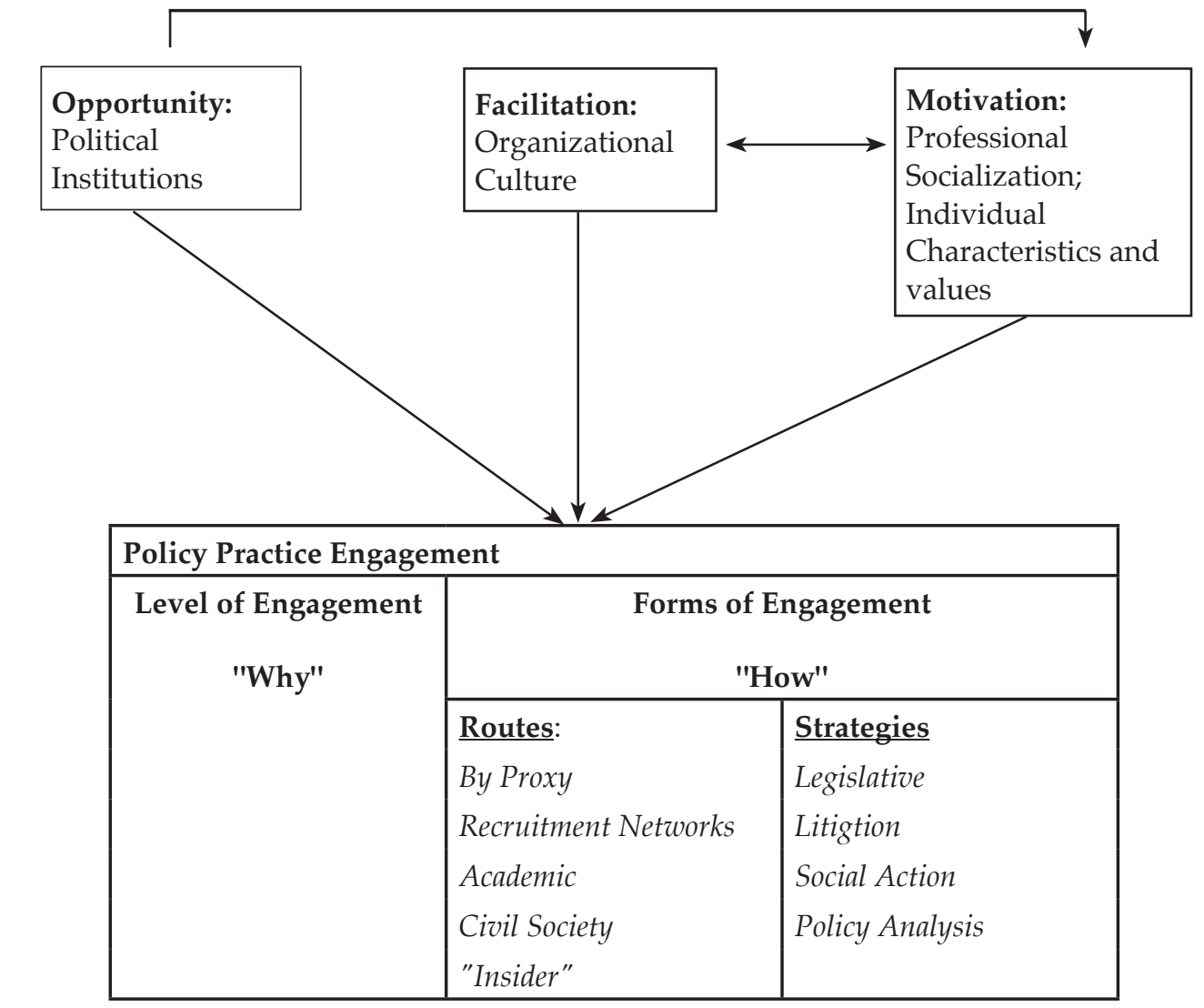

Reprinted from: Gal \& Weiss-Gal (2015).

By permission of Oxford University Press on behalf of the British Association of Social Workers. This figure not covered by the Creative Commons license of this publication. 
with policy advisors and decision-makers responsible for the complex problem of unaffordability. These legs are now described.

\section{Opportunity}

In their study, Gal and Weiss-Gal (2015) identified five pathways by which PPE can be advanced. First, "policy practice by proxy" (2015, p. 1085) represents actions taken on behalf of social workers by such bodies as the ANZASW. The second pathway extends the proxy route by the direct participation of members in advocacy and other actions such as submissions "initiated and organised by [their] social work organisations" (2015, p. 1085)—i.e., ANZASW.

A third, distinctive, pathway is expressed through social work academics. Policy practice by academia can take advantage of the tertiary sector's relative autonomy augmented by access to relevant data, critical approaches and the policy implications of their research (Gal \& Weiss-Gal, 2015, pp. $1085,1086)$. Such autonomy is exercised through the professional status of academics and their ability to access policy makers and the media.

Fourth, social workers can utilise the "civil society route" (Gal \& Weiss-Gal, 2015, p. 1086) as members or employees of "advocacy organisations, social movements and social welfare providers" (2015, p. 1086). In Aotearoa New Zealand, the Child Poverty Action Group (CPAG) is an example of an advocacy organisation (see, e.g., Asher \& St. John, 2016). Dr Mike O'Brien (ONZM) a former associate professor at the School of Counselling, Human Services and Social Work at the University of Auckland is wellknown for his PPE activities through CPAG.

Finally, Gal and Weiss-Gal (2015, p. 1086) describe the "insider route" as the vehicle by which social workers employed in the public sector can exercise direct policy practice through policy strategies. Alan Johnson, although not a registered social worker, is such an example. Alan is described as a "community activist" by CPAG where he is a researcher. He has also occupied governance roles in the Auckland Housing Association, the Auckland Community Housing Trust and as chair of Community Housing Aotearoa. Employed by the Ministry for the Environment, Alan has exercised significant policy influence through his co-authorship of A Stocktake of New Zealand's Housing, commissioned and published by the Ministry of Business, Innovation and Employment in 2018.

\section{Facilitation}

Gal and Weiss-Gal's second leg for potential PPE initiatives, facilitation, occurs primarily in the context of workplaces: organisations where most social workers are employed (2015, p. 1087). In evaluating the potential for PPE organisationally based actions, Gal and Weiss-Gal (2015, p. 1089) acutely observe that the "values, norms and behaviours" which constitute organisational culture become critical factors for several reasons. In their work on organisational culture, Schein and Schein (2016) suggest that, although professional actions are intended to express those values and norms, that may not actually be the case. Social workers may espouse the values in their Code of Ethics (ANZASW, 2019) but, in fact, those values may not be reflected in their behaviour (Argyris \& Schön, 1996; Schein \& Schein, 2016, p. 20). For example, managerialist thinking expressed as the drive towards greater efficiencies, effectiveness and economies may be so dominant in an agency that the ethical mandate to challenge structures which marginalise communities is rendered inoperative. At the other end of the spectrum, Monte Cecilia is a not-forprofit housing agency and a major employer of social workers. In a television interview with John Campbell in November 2020, the agency's chief executive Bernie Smith engaged in unmistakable policy advocacy. The interview title told the story: "More than a crisis"-Emergency housing group calls 
for urgent Government action as demand soars." Smith stated: "A year ago we would have five or ten families waiting for a housing solution; today we have 400 . We are one of 16 agencies in Auckland. We need a government that recognises that this is more than a crisis" (One News, 2020).

\section{Motivation}

In their third leg, Gal and Weiss-Gal (2015) focus on professional socialisation processes and Public Service Motivation (PSM) research $(2015$, p. 1089). They propose that these factors combine to enable social workers with the commitment and self-efficacy to take part in PPE actions. Why are social workers motivated to engage in policy practice? Gal and WeissGal suggest that a commitment to altruism which seeks to serve humankind activated, for example, by social justice (2015, p. 1089) is one such reason. One instance is found in the work of the University of Auckland social work academic Professor Jay Marlowe in working with refugees (Marlowe, 2018). The idea that "belonging," the first word in the title of his book, includes the mundane need for housing captures the altruistic motivation in Marlowe's work (Marlowe, 2018, p. 2).

Altruism, attraction to policy making, and identification with social justice come together to activate such PPE activities by social workers. Practitioners may then select one or more of the pathways described under Gal and Weiss-Gal's "opportunities" leg to initiate PPE action.

\section{Ethics and methodology}

The design of the research acted as a bridge between the literature, specifically Gal and Weiss-Gal's PPE framework, and the process by which participants supplied data. Analysis of those data provided substantive knowledge of housing unaffordability by which social workers can use the PPE framework.

\section{Ethics}

The University of Auckland Human Participants Ethics Committee (UAHPEC) approved the project in March 2018 as a low-risk study. Participants, subject matter experts in their fields, are professional public figures whose contact details were readily available. The ethics committee approved direct approaches by the researchers through an informed consent procedure inviting participation by email in which an information sheet and consent form were included.

\section{Methodology}

The project used a descriptive/exploratory design methodology. Descriptive research is required to understand the phenomenon of housing unaffordability and is the starting point for exploratory research which enables the investigation of a topic previously unexamined by social workers. Exploratory studies result in a range of causes and alternative options to address a specific problem (Sandhusen, 2008).

\section{Constructivism}

A constructivist paradigm was selected as an underpinning epistemology for the research. The rationale is drawn from Guba and Lincoln's (2005) "meaning-making activity" in which acquired knowledge is derived from the consensus of collective reconstructions (2005, pp. 195, 197). As a qualitative researcher, the author applied the ethical value of empathy when interpreting data. This epistemology led into Crotty's theoretical symbolic interactionist thinking: what makes sense to the researcher. The filter applied is the idea that the researcher "put[s] oneself in the place of the other" (Crotty, 1998, p. 75).

Symbolic interactionist thinking is reflected in the value of aroha expressed in the Aotearoa New Zealand Code of Ethics as love, concern, compassion, empathy (ANZASW, 2019, pp. 12, 15). The code makes a critical statement in this regard: social workers use professional judgement without being judgemental (ANZASW, 2019, p. 12, emphasis added). This was 
the position consciously adopted when interviewing participants and analysing data.

\section{Design}

The research question to which the eight participants responded reads:

"What critical questions inform the development of a diagnostic tool to identify the drivers of housing unaffordability?"

This question represents a wider investigation than is reported in this article: further findings will be presented in a future article. The critical issue for the current article is to provide relevant transdisciplinary information to social workers wishing to engage in PPE over the housing crisis. In designing a framework for research into housing unaffordability, it became self-evident that social workers do not generally possess the knowledge or skills to generate or analyse data relating to urban economics and city planning. The rationale for selecting the disciplines (Table 1) was two-fold. First, the subject matter expertise needed to supply that relevant knowledge to a social work audience required the input of those professional disciplines. Second, those disciplines provided the substance called for in the project's conceptualisation as an alliance between social work and other professionals.

\section{Analysis}

Qualitative data were thematically analysed using NVivo12 (Bazeley \& Jackson, 2013).

Initial analysis by the author was followed by an inter-rater process (Armstrong et al., 1997) carried out by a research assistant. A total of 547 thematic references divided into 15 nodes were identified following the inter-rater exercise. Using NVivo terminology, those 15 nodes were collapsed into two parent nodes, described in this article as categories. Each category had subcategories which are listed:

Category 1. The human factor: Housing
affordability as a human right
Sub-category 1: Severe
deprivation
Sub-category 2: Inadequate
income to meet housing costs
Category 2.
Political, economic and
housing affordability
Sub-category 1: Planning
regulations affecting the
human right to meet housing
needs
Sub-category 2: Soft political
power
Sub-category $3:$ Geographic-
specific factors

Table 1. Participants

\begin{tabular}{l|l|l} 
Participant designation & \multicolumn{1}{|c}{ Professional identity } & \multicolumn{1}{c}{ Location and status } \\
\hline Participant A & Private sector economist/developer & Tāmaki Makaurau, self-employed \\
\hline Participant B & Non-governmental social policy analyst & Tāmaki Makaurau, senior analyst in well-known NGO \\
\hline Participant C & Public policy advisor & Pōneke (Wellington) senior public servant \\
\hline Participant D & Public sector economist & Pōneke (Wellington) senior public servant \\
\hline Participant E & Public sector economist & Tāmaki Makaurau senior local government officer \\
\hline Participant F & Public sector urban planner and designer & Tāmaki Makaurau senior academic \\
\hline Participant G & Private sector housing strategist & Tāmaki Makaurau senior manager in NGO \\
\hline Participant H & Public sector city planner & Tāmaki Makaurau senior local government officer
\end{tabular}




\section{QUALITATIVE RESEARCH}

\section{Limitations}

As this is qualitative research, generalisations cannot be made. Although the participants came from public, private and not-for-profit sectors, a small sample of eight informants is, in itself, a limiting factor. The project and its findings are best seen as raising issues of interest to social workers by providing a perspective which lends itself to PPE.

\section{Results}

Two categories, (1) housing affordability as a human right and (2) political, economic and environmental factors informing housing affordability, have been presented. Together with social justice, human rights are seen as the primary value underpinning social work and compelled the research reported in this article. Investigating the second set of political, economic and environmental factors necessitated engagement with town planners, urban economists and housing analysts spanning the public and private sectors and non-governmental organisations.
Interdisciplinary relationships to advance common concerns are not uncommon in social work. Defining housing unaffordability through a social justice and human rights lens provides an empirical base to discuss research findings.

\section{Overview of findings}

Table 2 sets out an overview of the findings divided into the two categories identified in the previous section. As qualitative research, impactful or explanatory quotes have been included as illustrating the perspectives of selected participants. Their occupations have been listed after each verbatim quote with the purpose of capturing the views of diverse professional groups, enhancing the focus in this article on PPE. In respect of affordable housing, a measure of common ground exists between social work and the private sector as well as NGO and public sector occupational groups.

Definitions of categories 1 and 2 are appended at the end of this article as a glossary.

Table 2. Overview of Findings: Categories/Impactful Quotes/Number of Participants Who Referred to the Category

1. The human factor: housing affordability as a human right Quotes:

- [Unaffordability is] the biggest issue facing New Zealand in recent history. How could it not be? You have half the population paying two to three times what they should be for housing. They can't afford to feed themselves; they live in garages. That is unnecessary. (Private sector economist/developer)

- I think there is something inherently wrong in places like Auckland if our key workers like our teachers, our nurses, [and] our police can't afford to buy a house, something really wrong. When you have got key people that provide services that we all need and they can't get on the housing ladder there is something fundamentally wrong (Private sector housing strategist)

2. Political, economic and environmental factors

Quotes:

- Well-paid planners telling people how they can't live, but are happy with people living in cars and under bridges... I believe planning and building control rules actually impinge on human rights (Senior NGO analyst)

- The planning profession and local government control supply [of] zoned land and the rules that enable you to develop that land. If supply is constrained prices go up-it is that simple. (Private sector economist/developer)

- When land is constrained it balloons in price. In Auckland the underlying cost of land is about $\$ 58,000$ per section but the price of land is $\$ 580,000$ a section. So the price is 10 times bigger than the cost. (Public sector economist) 


\section{Category 1: Housing affordability as a human right}

The references to human rights and social justice from a group of six non-socialwork professionals demonstrate that those concerns are not confined to social work. In addition, the awareness of those concerns suggests that applying the routes and strategies listed in the "how" of PPE offers productive potential.

In one instance, the awareness of a social justice dimension to housing was far more acute. Participant A, a private sector economist/ developer, identified unaffordability as:

... the biggest issue facing New Zealand in recent history. How could it not be? You have half the population paying two to three times what they should be for housing. They can't afford to feed themselves; they live in garages. That is unnecessary.

The author suggests that social workers would find common ground with the views of this private sector economist/developer.

It is noteworthy that a participant who derives much of his income from property development is convinced that unaffordability is not only the largest single issue facing the country, but is also of the view that marginalised populations reduced to living in garages is unnecessary.

Participant B-a non-governmental policy analyst, although not a qualified social worker-saw human rights as underpinning the right to housing of human communities. In his view, this right includes building a dwelling, but local body regulations have in effect removed that right. He also believes that under Te Tiriti, Māori possess the right to construct a dwelling on traditionally owned land. Participant B's perspective clearly prioritises human rights and a society that integrates Te Tiriti into policy formulation and implementation. He argues that regulations which govern planning, land supply and zoning have marginalised those human rights, a tension that will be explored later in this article. Participant B also articulated a view that brought him into alignment with an interpretation held by the social work profession:

Interviewer: Do you think in fact we do face a housing unaffordability problem?

Response: Yes we do but I think it is more to do with the distribution of income ... the housing affordability problem is a consequence of the misdistribution of income in our society. It is a symptom of a very unequal society.

Such views are evidence of a systemic or ecological perspective in which diverse components of society-in this case, home ownership and income distributionbecome interdependent relationships.

Other participants concurred with the view that city planning influences housing affordability but employed different analytical lenses in coming to that opinion. Participant B, the non-governmental social policy analyst, bluntly criticised "[w]ellpaid planners telling people how they can't live, but are happy with people living in cars and under bridges... I believe planning and building control rules actually impinge on human rights." A sense of outrage is evident in those comments, connecting this participant with social work ethics coming from the UDHR and notions of social justice. He added: "I am a planner by background. I would argue that people have a right to build housing on their land.".

The social justice theme also emerged in the comments of Participant F, a public sector urban planner in relation to housing affordability as a wicked problem. He identified people from lower socioeconomic groups as suffering disproportionately from 
this wicked problem and specified Māori and Pasifika as being overrepresented among those groups. Participant F also drew attention to "a lot of white people in the same boat." Participant G, the private sector housing strategist, drew attention to what she described as the "inherent wrongs" in our communities:

I think there is something inherently wrong in places like Auckland if our key workers like our teachers, our nurses, [and] our police can't afford to buy a house, something really wrong. When you have got key people that provide services that we all need and they can't get on the housing ladder there is something fundamentally wrong [emphases added].

This acknowledgment by a private sector strategist that unaffordable housing in our community is "fundamentally wrong" illustrates an awareness of social justice as a moral issue. Participant G sees the provision of housing as meeting a greater need than shelter by individual families. She articulated a deeply held "vision" by which housing connects and strengthens whole communities.

We now turn to the second category in the findings: the views of participants on political, economic and environmental factors as these factors relate to housing affordability.

\section{Category 2: Political, economic and environmental factors relating to housing affordability}

Data analysis giving rise to the second category reveals no less than $5 \frac{1}{2} 2$ times greater frequency of transcript occurrences relating to political, economic and environmental factors than housing affordability as a human right. Planning regulations incorporate environmental factors. The thinking that informed the 1992 Rio Declaration has been integrated into
New Zealand environmental law (MfE, 1993, pp. 5-7.) All eight participants made reference to these category 2 factors.

Participant A, the private sector economist/ developer, drew particular attention to the influence of Agenda 21, now known as the 2030 Agenda for Sustainable Development. His overall analysis emerged in this exchange:

Interviewer: You are saying that Agenda 21 informs the way planners think?

Response: That is the foundation of the planning profession at this point. Their primary objective is the implementation of Agenda 21 through the smart growth documentation. Smart growth is the city's part of the implementation of Agenda 21.

Smart cities in the context of this view are sustainable spaces which are not harmful to the environment (Eremia et al., 2017, p. 14). Participant A extended his views by directly linking the implementation of Agenda 21 with unaffordable housing. He considers that the planning profession believes that achieving the goals set by Agenda 21 to address climate change are justified even if those measures increase rents, for example, by $\$ 200$ per week: "That would be a price worth paying if it addressed the global warming issue."

The theme of land costs as a factor in housing affordability was voiced by several participants. Participant A, the private sector economist/land developer, attributes price increases to planners and local government who together "control" the supply of land. In his view, this becomes a simple economic equation: if supply is constrained, prices increase. That view is also held by the public sector economist, Participant D: 
When land is constrained it balloons in price. In Auckland the underlying cost of land is about $\$ 58,000$ per section but the price of land is $\$ 580,000$ a section. So the price is 10 times bigger than the cost.

Participant B as an NGO social policy analyst concurred with the views of the land developer (Participant A) regarding urban land release policies in his statement that "The cost of land has made housing unaffordable." It is noteworthy that a social policy analyst with a keen sense of human rights agrees with a private economist and land developer by focusing on the cost of land as the primary factor in unaffordability. Similarly, public sector economist, Participant D, commented that "in a wellfunctioning market, land is usually only $20 \%$ of the price of a house."

The views about land supply as a major factor in pushing house prices up was not shared by two public sector participants, an economist (Participant E) and town planner (Participant F) respectively. They proposed that expensive housing is evidence of a "successful city" because people are willing to pay "anything" to live in cities such as Auckland. The city's location on the water, pleasant climate, well-developed service sector, strong international connections, and safe communities create demand which translates to higher prices.

Participant F compared affordable Midwest US cities-that is, where dwellings cost no more than three times the median household income-such as Detroit with "liveable" cities, including Auckland. He attributed their affordability to economic hardship because of unemployment and poor city amenities. Participant C, a senior public policy advisor, was arguably more candid in his assessment, drawing attention to the view that affordable cities in states such as Texas espouse neoliberalism with a "completely unregulated market." He perceived this environment as one where the focus is on making capital returns and commented: "I really don't like the Houston market. I don't like the absence of regulation." This suggests an ideological difference of opinion.

\section{Discussion}

This article has sought to apply the literature and the perspectives of subject matter experts to enable social workers to understand housing unaffordability. The author has argued that a commitment to human rights in relation to housing affordability is needed; that social workers must develop an understanding of the political, economic and environmental factors relating to housing affordability; and finally, that social workers must understand factors that contribute to housing unaffordability and its extreme consequence, homelessness. By grasping these factors, social workers will be enabled to engage with policy advisors and decision-makers responsible for the wicked problem of unaffordability through the PPE framework (Gal \& Weiss-Gal, 2015).

The author proposes that, between the literature and the participants, a consensus has established a common understanding on three issues: Chris Hipkins (2018) has accurately identified a housing affordability crisis; there is increasing homelessness; housing unaffordability is appropriately addressed as a human right through the UDHR (UNGA, 1949) and indeed has been taken up by the Human Rights Commission by its announcement of a national enquiry into the housing crisis in August 2021 (Hunt, 2021). There is less consensus on the factors that have contributed to the crisis. The grey literature and several participants suggest that housing and environmental regulations designed to apply the United Nations' sustainable development goals have contributed to unaffordability. Other participants propose that the desirability of living in cities such as Auckland has increased demand and therefore housing costs. The author adopts the perspective that there is no single factor precisely 
because of the formulation of housing unaffordability as a wicked problem (Grint, 2005).

The author proposes that tangible examples exist in Aotearoa New Zealand of the application of the "three legs" of the PPE Framework (Gal \& Weiss Gal, 2015): opportunity through political institutions, facilitation afforded by social work's organisational and professional culture, and professional and individual motivation. The work of such advocates as Dr Mike O'Brien in the Child Poverty Action Group; Alan Johnson in the same context and additionally in the housing field through commissioned research by the Ministry of Business, Innovation and Enterprise; Bernie Smith's public advocacy as chief executive of a major housing non-governmental agency; and the work of Professor Jay Marlowe in working with and advocating for refugees are all, in their diverse fields, models for the PPE.

\section{Conclusion and implications}

Food security and the human need for shelter are foundational to well-being. This article proposes that an effective focus on housing requires the social work profession in Aotearoa to engage in three interrelated actions.

The first is to establish a transdisciplinary research team comprising social workers, urban economists, town planners, social policy analysts, and housing strategists. The initial purpose of this group will be to select a research director and design (and secure funding for) a project that will investigate the categories identified in this article as indicative initial pathways. The longer-term objective will be to set out a solid, researchinformed base which will encourage crossparty political support to take effective action on the affordability crisis.

The second action will be to develop a professional interest group, possibly under the umbrella of the ANZASW, but ideally comprised of diverse disciplines, who will acquire expertise in Gal and WeissGal's (2015) PPE framework. Depending on time commitments, this group could draw members from the transdisciplinary research team. The purpose of this group will be to practically apply the PPE, taking advantage of the three legs identified by the framework in conjunction with the research emerging from the transdisciplinary team.

The last action will require the involvement of media skills activists such as Alan Johnson and Bernie Smith in the project. Their task will be twofold: place the housing crisis issue constantly before local and national politicians and the public at large; and train the professional interest group in the art of public relations.

In launching such actions, it is probably impossible to predict the outcomes. But the journey must begin.

\section{Acknowledgements}

The author expresses appreciation to:

Ms Kendra Cox, Master of Social Work (Hons) for performing an inter-rater data analysis;

Dr Ellie Bahmanteymouri, who was an associate investigator in the project; and

Mr Hitendra Patel, Master of Social Work Professional for an initial contribution to the literature review.

The most helpful work of the anonymous peer reviewers.

The project was funded by the Public Policy Institute of The University of Auckland.

Accepted 2 December 2021

Published 23 December 2021 


\section{Glossary}

Definitions of categories in Table 2

\section{The human factor: Housing affordability as a human right} Definition: The UDHR states that "Everyone has the right to a standard of living adequate for the health and well-being of himself and of his family, including housing and medical care" (article 25) (UNGA, 1949).

\section{Political, economic and environmental factors}

\subsection{Political factors including legislation}

Definition: Urban planning is usually defined as the implementation of policy-makers' decisions; "planners in politics" refers to the activities of planners with a political awareness about policy-making; "politics in planning" refers to the intervention of politics in management; and 'politicians in planning' refers to the politician's involvement in planning processes, motivated by political reward. Many actors participate in the urban planning process: planners, bureaucrats, politicians, entrepreneurs, as well as the general public. (Auerbach, 2012, p. 49)

\subsection{Planning, land supply, zoning regulations}

Definition: The "urban planning system" is defined as the statutory and governance frameworks that incorporate decisions by councils, central government and the private sector about urban spaces. The New Zealand urban planning system is predominantly guided by three pieces of legislation: The Local Government Act 2002 (LGA)

The Resource Management Act 1991 (RMA) (currently under review)

The Land Transport Management Act 2003 (LTMA)

\section{References}

Adamson, C. (2014). A social work lens for a disasterinformed curriculum. Advances in Social Work \& Welfare Education, 16(2), 7-22.

Amore, K. (2019). Everyone counts: Defining and measuring severe housing deprivation (homelessness) [Unpublished doctoral dissertation]. University of Otago.

Aotearoa New Zealand Association of Social Workers. (2019). Code of Ethics (Rev. ed.). https://www.anzasw. nz/code-of-ethics/

Argyris, C., \& Schön, D. A. (1996): Organizational learning II: Theory, method and practice Addison-Wesley.

Armstrong, D., Gosling, A., Weinman, J., \& Marteau, T. (1997). The place of inter-rater reliability in qualitative research: An empirical study. Sociology, 31(3), 597-606.

Asher, I., \& St. John, S. (2016). Child poverty and health in New Zealand. The Policy Observatory. https://thepolicyobservatory.aut.ac.nz/_data/assets/ pdf_file/0005/75092/Asher-and-St-John-Child-PovertyHealth-in-NZ-v3.pdf

Auerbach, G. (2012). Urban planning: Politics vs. Planning and Politicians vs. Planners. Horizons in Geography, 79/80, 49-69.

Bazeley, P., \& Jackson, K. (2013). Qualitative data analysis with NVivo (2nd ed.). Sage.

Crotty, M. (1998). The foundations of social research: Meaning and perspective in the research process. Sage.

Dominelli, L. (2012). Green social work: Polity.

Eremia, M., Toma, L., \& Sanduleac, M. (2017). The Smart City Concept in the 21st Century. Procedia Engineering, 181, 12-19. https://doi.org/10.1016/j.proeng.2017.02.357
Gal, J., \& Weiss-Gal, I. (2015). The "why" and the "how" of policy practice: An eight-country comparison. British Journal of Social Work, 45(4), 1083-1101. https:// doi.10.1093/bjsw/bct179

Grint, K. (2005). Problems, problems, problems: The social construction of "leadership." Human Relations, 58(11), 1467-1494. https://doi.10.1177/0018726705061314

Guba, E. G., \& Lincoln, Y. S. (2005). Paradigmatic controversies, contradictions, and emerging confluences. In N. K. Denzin \& Y. S. Lincoln (Eds.), The SAGE handbook of qualitative research (3rd ed., pp. 191-215). Sage.

Harvard T. H. Chan School of Public Health. (2021). Harvard Transdisciplinary Research in Energetics and Cancer Center: Definitions. https://www.hsph.harvard.edu/trec/ about-us/definitions

Hipkins, C. (2018, October 2), PPTA conference speech [Press release]. https://www.beehive.govt.nz/speech/ ppta-conference-speech

Human Rights Commission Te Kāhu Tika Tangata. (2017). The human right to adequate housing in New Zealand: Human Rights Commission. https://www.hrc.co.nz/fil es/4215/1363/5639/2017_07_25_-_Right_to_housing_ flyer_-_updated.pdf

Hunt, P. (2021, August 2). Human Rights Commission launches national inquiry into housing crisis. C. Dann (Ed.). Morning Report RNZ. https://www.rnz.co.nz/news/ national/448245/human-rights-commission-launchesnational-inquiry-into-housing-crisis

International Federation of Social Workers. (2014). Global definition of social work. http://ifsw.org/policies/definitionof-social-work/ 
One News. (2020). "More than a crisis" - Emergency housing group calls for urgent Government action as demand soars. https://m.youtube.com/watch?v=m_VL-JtCTo\&t=209s

Howden-Chapman, P., \& Eaqub, S. (2018). A stocktake of New Zealand's housing. Ministry of Business, Innovation \& Employment.

Kemp, S. P., Palinkas, L. A., \& Mason, L. R. (2018). Create social responses to a changing environment. In R. Fong, J. Lubben, \& R. P. Barth (Eds.), Grand challenges for social work and society. Oxford Scholarship Online.

Marlowe, J. (2018) Belonging and transnational refugee settlement: Unsettling the everyday and the extraordinary. Routledge.

Ministry for the Environment. (2018). National Policy Statement on Urban Development Capacity: Summary evaluation report of Housing and Business Development Capacity Assessments for high-growth urban areas. Wellington: Author.

Ministry for the Environment \& Local Government Association. (1993). Making connections: An overview of Agenda 21. Wellington: Author.

Ministry for the Environment and Ministry of Business Innovation and Employment. (2016). Recommendations and decisions report on the Policy Statement on Urban Development Capacity. Wellington: Author.

Ministry of Foreign Affairs and Trade. (n.d.). Sustainable development goals. https://www.mfat.govt.nz/en/peacerights-and-security/work-with-the-un-and-other-partners/ new-zealand-and-the-sustainable-development-goals-sdgs/

Parker C. (2015). Housing supply, choice and affordability: Trends, economic drivers, and possible policy interventions. Auckland City Council.

Parker, D. (2018, March 28). Economic growth within environmental limits. [Address to the Resource Management Law Association Seminar]. https://www.beehive.govt.nz/speech/economic-growthwithin-environmental-limits

Rittel, H., \& Webber, M. (1973). Dilemmas in a general theory of planning. Policy Sciences, 4(2), 155-169. https://10.1007/bf01405730

Sandhusen, R. L. (2008). Marketing (4th ed.). Barron's Business Review Series, Simon \& Schuster.

Schein, E. H., \& Schein, P. (2016). The structure of culture. In Organizational culture and leadership (5th ed., pp. 17-30). John Wiley.

Simmons, B. M. (2012). Evidence-based practice, person-inenvironment, and clinical social work: Issues of practical concern. Smith College Studies in Social Work, 82(1), 3-18. https://doi.10.1080/00377317.2011.638889

Statistics New Zealand/Tatauranga Aotearoa. (2021). Household economic statistics (Expenditure). http://datainfoplus.stats.govt.nz/ltem/nz.govt. stats/1bff2593-6872-4995-b71a-506b4612902c?\&_ ga $=2.131977095 .940982178 .1629849152-$ 1893885349.1629849152\#/nz.govt.stats/1bff2593-68724995-b71a-506b4612902c/107

Tay, L., \& Diener, E. (2011). Needs and subjective wellbeing around the world. Journal of Personality \& Social Psychology, 101(2), 354-365.

The Treasury. (2017). Briefing for the incoming Minister of Finance: The Treasury. https://www.treasury.govt.nz/ sites/default/files/2017-12/bim-tsy-finance-oct17.pdf
Twyford, P. (2019, December 7). Speech to Government Economics Network 2019 Conference. https://www. beehive.govt.nz/speech/speech-government-economicsnetwork-2019-conference

United Nations General Assembly. (1949). Universal declaration of human rights: Final authorised text. United Nations Department of Public Information.

Weaver, R. (1984). Ideas have consequences. University of Chicago Press.

Woolley L. (2014). Housing support services for families/ whānau and individuals who have experienced homelessness: A case study of VisionWest Community Trust, West Auckland [Unpublished master's thesis]. UNITEC, Auckland. 